American Journal of Pharmaceutical Education 2019; 83 (6) Article 6805.

\title{
RESEARCH
}

\section{Student and Graduate Perceptions Regarding Canadian-based Accreditation of a Pharmacy Program in Qatar}

\author{
Kyle John Wilby, PharmD, Maha Alamri, BSc Pharm, Saba Monfared, BSc Pharm \\ College of Pharmacy, Qatar University, Doha, Qatar
}

Submitted September 21, 2017; accepted March 26, 2018; published August 2019.

\begin{abstract}
Objective. To determine student and alumni perceptions of a Canadian-based pharmacy degree accreditation in a Middle Eastern setting and to explore the impact on patient care practices.

Methods. Current and former Doctor of Pharmacy students from Qatar University were recruited to participate in the study. Three focus groups were conducted with a total of 14 participants (39\% of total population). Focus group discussions were recorded and transcribed verbatim. Transcripts were coded using a bottom-up, grounded theory approach to identify overarching themes related to the study objectives.

Results. Data analysis of participants' comments revealed three key themes regarding university accreditation by an international organization: influence on education, influence on patient care, and influence on the individual. Overall, participants responded positively toward international accreditation, as it was perceived to ensure the quality of education by meeting international standards, improve patient care through clinical training, and provide greater individual career opportunities through reputability. Participants responded negatively toward some aspects of accreditation: it was perceived to increase student workload, lacked recognition and did not result in differentiation in job-related duties, and was perceived to be the reason for training gaps related to culture and language within the accredited curriculum.

Conclusion. Participants perceived international accreditation positively for its influence on education and patient care; however, some misconceptions and negative perceptions existed regarding its influence on the individual practitioner.
\end{abstract}

Keywords: accreditation, program evaluation, evaluation, qualitative

\section{INTRODUCTION}

Accreditation as defined by the European Consortium of Accreditation (ECA) is "a formal and independent decision, indicating that an institution of higher education and/or programs offered meet certain standards." Accreditation of a program is a way to facilitate an appropriate learning environment that ensures minimum standards are met and graduates are able to achieve the required competence as professionals. ${ }^{2}$ It is a major focus of health science disciplines, including pharmacy. The General Pharmaceutical Council (GPC; United Kingdom), the Accreditation Council for Pharmacy Education (ACPE; United States), and the Canadian Council for Accreditation of Pharmacy Programs (CCAPP; Canada) are just three organizations that offer credentialing to pharmacy programs within each respective country. ${ }^{3-5}$

Corresponding Author: Kyle John Wilby, School of Pharmacy, University of Otago, PO Box 56, Dunedin, New Zealand. Tel: +64-3479-7325. E-mail:

kyle.wilby@otago.ac.nz
In some cases, accreditation activities can be expanded to postgraduate and continuing education programs.

There is an increasing global trend for programs in countries with developing education systems to seek international accreditation from Western organizations. ${ }^{6,7}$ Some organizations, such as CCAPP, offer full accreditation of international programs according to Canadian and/or international standards. ${ }^{5}$ Others, such as ACPE, only offer certification to programs outside of the United States (with the one exception being the Lebanese American University in Beirut). ${ }^{4}$ Rationale for this movement by international programs may include the desire to improve quality of programming, as well as for prestige, recognition, financial gain, and marketing purposes. For whatever reason organizations participate in awarding international accreditation, students are the major stakeholders that are intended to benefit from this credentialing. ${ }^{8}$ Although accreditation is typically celebrated as a positive milestone, how being awarded Western-based accreditation influences students and alumni of international programs is unknown. 


\section{American Journal of Pharmaceutical Education 2019; 83 (6) Article 6805.}

There is a paucity of literature exploring the influence of accreditation on student outcomes. Van Zanten and colleagues supported the value and usefulness of accreditation in Mexico and the Philippines by linking accreditation with improved test scores among medical students. ${ }^{9}$ The researchers found that attending an accredited school was associated with increases in first-attempt pass rates on the United States Medical Licensing Examination (USMLE) by $15.9 \%$ for Mexican citizens and $29.2 \%$ for Philippine citizens. ${ }^{9}$ Two other studies conducted in the United Arab Emirates and Turkey examined medical student perceptions of accreditation and largely found that students perceived accreditation as a positive influence on the quality of educational programing. ${ }^{10,11}$ While these studies provide some evidence that international accreditation may have positive effects on medical students, no study was found that identified its effect on pharmacy students. Furthermore, these studies lacked an in-depth approach to determine both the positive and negative perceptions regarding the impact of accreditation from student perspectives.

The aim of this study was to determine student and alumni perceptions (defined as beliefs or opinions) of accreditation of international pharmacy degree programs and to explore any perceived impact on patient care practices.

\section{METHODS}

This qualitative study using focus groups was approved by the institutional review board at Qatar University. A qualitative approach was chosen in order to inform development of research methods for future quantitative studies. Focus groups allowed us to explore participants' perceptions in depth, while ensuring we gained an adequate understanding and interpretation of their views on accreditation and related concepts. The study took place at Qatar University in Doha, Qatar. The College of Pharmacy at this institution maintains full accreditation by the CCAPP for the Bachelor of Science in Pharmacy and the one-year post-baccalaureate Doctor of Pharmacy (PharmD) program. All students enrolled in the programs were female.

We sought to recruit past and current students from the PharmD program at Qatar University to participate in the study. The PharmD students and alumni were chosen as these students all had completed at least one year of direct patient care practice and were therefore best suited to answer questions related to the university's research objectives. Participants were eligible for inclusion if they were a current student or graduate from the full-time PharmD program (total population $=42$ students and alumni) and were currently practicing in a direct patient care area within Qatar (total eligible $=36$ students and alumni). Graduates outside of Qatar, not currently working, or working in a non-patient care area were excluded. Participants were recruited using convenience sampling. An email invitation was sent to the entire eligible population, and responders were contacted to provide further study details. Those agreeing to participate were scheduled for one of three pre-planned focus groups. Written informed consent was provided upon arrival at the focus group. No compensation was provided.

A topic guide was developed based on the study objectives. Prior to any study procedure, investigators met to document their own perceptions of accreditation and expected results. During this process, each investigator verbalized their expectations of the potential findings and documented the group's discussion points in order to be aware of potential investigator bias in data analysis and interpretation. We then conducted one pilot focus group with four current PharmD students who were part of the eligible population according to the inclusion criteria. This pilot study allowed us to refine the topic guide for the focus groups and gain an initial understanding of how participants perceived the concept of accreditation. After finalization of the topic guide, three focus groups were scheduled. Two investigators facilitated each focus group. Upon arrival, participants were welcomed and asked to provide written informed consent. Discussion then ensued and lasted for 45 to 60 minutes. The discussion was digitally recorded. Upon completion of each focus group, the recording of the session was transcribed verbatim. An investigator who did not serve as a facilitator for the focus groups checked each recording and transcript for errors.

Two investigators coded each transcript independently using an open coding technique. The primary investigator, who had training and extensive experience in qualitative data analysis, coded all transcripts. Other coders had received training in qualitative research techniques and analysis. Transcripts were segmented into words, sentences, or phrases that belonged to a single idea. Each segment was then assigned a unique code. Codes were combined into categories and reviewed by all investigators. Overarching themes, based on codes and interpretations, were identified and agreed upon by all investigators. A member (ie, participant) checking procedure where final results were given back to participants for comment was implemented to support the validity of the results. 


\section{American Journal of Pharmaceutical Education 2019; 83 (6) Article 6805.}

\section{RESULTS}

Thirty-six potential subjects were eligible for participation in the focus groups. From this population, 15 subjects responded to the emails and agreed to participate in one of three focus groups. This resulted in a final sampling of $42 \%$ of the total eligible population. One of the scheduled participants for focus group 2 cancelled immediately prior to the session because of health concerns. Demographics of participants are given in Table 1. The three focus groups had six, three, and five participants, respectively.

Eighty-seven different codes were assigned to the data. Upon analysis, these codes were combined into seven unique categories. Definitions of categories were developed based on examples provided within the data and are given in Table 2. These categories included quality of education, adaptability, opportunities/privileges, patient care, curricular influence, recognition, and workload. Finally, these categories were interpreted under three themes, namely accreditation's perceived influence on education, patient care, and the individual practitioner.

Theme 1, influence on education, related to the categories of quality of education, adaptability, and curricular influence. Perceptions related to accreditation's influence on education were focused on standards, quality, and content. Specifically, participants conveyed that accreditation contributed to many aspects, such as a higher level of communication skills, ability to use acquired research skills, and knowledge to provide evidencebased recommendations. Participants overwhelmingly perceived these aspects as positive contributions to the curriculum and program. There were also comparisons made from an international perspective, where participants felt they were being prepared to practice in settings that were more advanced (Appendix 1).

Some negative perceptions were discussed under the theme of accreditation's influence on education. First, participants felt that international requirements to teach certain topics (ie, Canadian law) were irrelevant and not useful for practice in Qatar. Similarly, participants felt the

Table 1. Demographics of Focus Group Participants in a Study to Determine Pharmacy Student and Alumni Perceptions Regarding International Accreditation of a Pharmacy School in Qatar

\begin{tabular}{lc}
\hline Demographic Variable & No. (\%) \\
\hline Female & $14(100)$ \\
Alumni & $9(64)$ \\
Current students & $5(36)$ \\
Years of experience [Mean (SD)] & $2.5(1.4)$ \\
\hline
\end{tabular}

program lacked Arabic-language competencies required for local practice, as the program is conducted entirely in English. Participants related this specifically to the use of Western standardized patients during simulation exercises and assessments.

Another negative aspect was the perceived disregard for knowledge-based topics, such as the foundational sciences. Participants felt that they were well prepared in terms of communication and skills, yet lacked knowledge that was expected of them in practice. There was tension regarding this point between focus groups, as those graduating earlier defended that the skills they learned enabled them to overcome knowledge gaps upon entering practice.

Theme 2, influence on patient care, related to the categories of adaptability, patient care, and curricular influence. The PharmD candidates and graduates reported that curriculum provided higher standards of knowledge and skills, and thus contributed to better patient care. They specifically related curricular strength to practice capabilities. They also explained that international accreditation focused on providing clinically oriented education, mainly through experiential training, and that this helped in raising their awareness of different approaches to assess and treat patients.

The participants also stated that international accreditation contributed to the development of pharmacy practice in Qatar by improving the way other health care providers work with clinical pharmacists. Moreover, participants agreed that the accredited program trains students to act in any situation, such as dealing with patients from a variety of cultural backgrounds, and imparts the skills for acquiring new information by accessing reliable sources to look for new guidelines and diseases. All of these points were perceived to contribute to better patient outcomes.

Theme 3, influence on the individual, related to the categories of quality of education, opportunities/ privileges, recognition, and workload. Perceived influences of accreditation on individuals encompassed many career, student, and social aspects. Almost all of the participants gave credit for having better jobs opportunities upon graduation, both in Qatar and abroad, to the program being accredited. The ability to take on advanced clinical roles upon graduation was also seen as a benefit for participants' own professional development. International postgraduate opportunities were also mentioned. Many participants stated that the program having international accreditation would help students who planned to study abroad, especially in Canada, as some requirements might be exempted because of the similarity of the program with the Canadian system. 


\section{American Journal of Pharmaceutical Education 2019; 83 (6) Article 6805.}

Table 2. Definitions and Relationships of Categories with Overall Themes Identified From Focus Groups with Pharmacy Students and Alumni Regarding International Accreditation of a Pharmacy School in Qatar

\begin{tabular}{|c|c|c|c|c|}
\hline Category & Definition & $\begin{array}{l}\text { Quality of } \\
\text { Education }\end{array}$ & $\begin{array}{l}\text { Patient } \\
\text { Care }\end{array}$ & Individual \\
\hline $\begin{array}{l}\text { Quality of } \\
\text { Education }\end{array}$ & $\begin{array}{l}\text { Accreditation enhances advanced research skills, communication abilities, } \\
\text { evidence-based health care skills, and systematic approach. Conversely, } \\
\text { accreditation may decrease emphasis and result in knowledge gaps for } \\
\text { pharmaceutical science subjects. }\end{array}$ & $\mathrm{X}$ & & $\mathrm{X}$ \\
\hline Adaptability & $\begin{array}{l}\text { Accreditation enables graduates to prepare for diverse patient care situations } \\
\text { and helps with overcoming challenging clinical environments. }\end{array}$ & $\mathrm{X}$ & $\mathrm{X}$ & \\
\hline $\begin{array}{l}\text { Opportunities/ } \\
\text { Privileges }\end{array}$ & $\begin{array}{l}\text { Accreditation supports career and post-graduate education opportunities, } \\
\text { especially in international settings. It may also provide advantages with } \\
\text { respect to being assigned clinical duties in practice. }\end{array}$ & & & $\mathrm{X}$ \\
\hline Patient Care & $\begin{array}{l}\text { Accreditation promotes patient-centred practice, enhances collaborative care } \\
\text { and leads to improvement in provided health services. }\end{array}$ & & $\mathrm{X}$ & \\
\hline $\begin{array}{l}\text { Curricular } \\
\text { Influence }\end{array}$ & $\begin{array}{l}\text { Accreditation is perceived to align curricular material with policy and } \\
\text { practice. It is also perceived to create curricular imbalances between } \\
\text { pharmaceutical and clinical courses, and language and cultural } \\
\text { competencies. }\end{array}$ & $\mathrm{X}$ & $\mathrm{X}$ & \\
\hline Recognition & $\begin{array}{l}\text { Accredited programs are reputable and also promote feelings of confidence } \\
\text { and uniqueness on individuals. Conversely, there may be a lack of } \\
\text { recognition of what accreditation truly means by students and also a lack of } \\
\text { recognition or value by certain employers and/or licensure organizations, } \\
\text { especially those located abroad. }\end{array}$ & & & $\mathrm{X}$ \\
\hline Workload & $\begin{array}{l}\text { Requirements for accreditation may increase student stress with respect to } \\
\text { program admission requirements, increased course load, and/or increased } \\
\text { expectations in terms of performance level. }\end{array}$ & & & $X$ \\
\hline
\end{tabular}

Recognition and personal satisfaction emerged as positive attributes of completing an accredited program of study. All of the participants agreed that the program being accredited gave them an added sense of confidence and pride, as they know that they received or were receiving a high standard of education that was comparable to that received in advanced countries like Canada. They also added that accreditation meant that other health care providers would trust their recommendations more. On the other hand, some participants raised concerns about lack of recognition and differentiation in their careers in spite of their advanced training as graduates of accredited and non-accredited institutions are sometimes treated the same in terms of salary and job title, which some considered to be unfair. Some participants mentioned that colleagues holding degrees from non-accredited institutions did not understand the advanced clinical services that graduates from accredited institutions were trained to do.

Finally, a major complaint of students and alumni was the excessive workload, in terms of courses and assessments, which they perceived has been added to the curriculum to meet accreditation requirements. They believed that the extra workload caused them to focus more on getting good grades rather than gaining the actual ben- efit of learning. However, they perceived the increased requirements for entry into the program, including application requirements, had strengthened the program.

\section{DISCUSSION}

This qualitative focus group study explored student perceptions of international pharmacy program accreditation relating to education and practice. We found that students perceived accreditation to influence the quality of education, patient care, and ultimately themselves as individuals. Our findings support the notion that accreditation can positively influence education and practice, but might also have several negative implications, especially related to perceived effects on the individual. The themes identified in our study are largely supported by data obtained from medical students. Ibrahim and colleagues identified five themes relating to students' perceptions of accreditation: better quality of education, increased opportunities, meets high international standards, improved structure, and better patient care. ${ }^{10}$ The study by Yüksel concluded that the benefits of accreditation were perceived to be largely related to program quality, including quality assurance of curricular programming. ${ }^{11}$ In addition to the similarities between 


\section{American Journal of Pharmaceutical Education 2019; 83 (6) Article 6805.}

our findings and those in the existing literature, our study exposed previously undocumented strengths as well as weaknesses that are important for determining the impact of accreditation on students and alumni and developing future research, as discussed below.

We found that students perceive that accreditation positively influences the quality of education. As demonstrated by the results, the major focus on clinical capabilities and pharmacy practice skills was believed to have arisen from the accreditation requirements, and they perceived this as a program strength. This is in line with previous findings from studies with medical students; however, our study did not use objective measures to assess improvement in student performance before and after accreditation was achieved. ${ }^{9-11}$ Conversely, some participants recognized that the increased focus on skills development resulted in less emphasis being given to courses focused on building foundational knowledge, especially in the pharmaceutical sciences. While this emerged as a common concern across all focus groups, the proximity of some students to graduation may have biased this result. This finding, however, is an important indicator for pharmacy programs to assess and ensure that students in their final year have achieved all intended outcomes.

A second major finding was that students perceived that a university attaining accreditation positively influenced patient care. This was in line with perceptions identified among medical students in the United Arab Emirates. ${ }^{10}$ This is an interesting finding, as it supports accreditation as an accelerator of practice change in developing health systems. One could hypothesize that accreditation-related curricular refinements could produce more clinically competent graduates who would then stimulate practice change among their practice colleagues after graduation. While this study provides student perceptions about accreditation, exploring the perceptions of practice-based administrators and/or patients would also be interesting.

A final major finding was that accreditation influences students both positively and negatively. The positive perceptions (ie, job opportunities, greater perceived competence, clinical duties) were expected and in line with previous studies from medical students. ${ }^{9-11}$ The negative findings, however, were largely unexpected. This study exposed misconceptions that students have about international accreditation, and these should be addressed. Specifically, students believed their degree certificate would be generated from a Canadian institution, or at the very least, the Canadian institution would provide documentation on the student record of the accreditation status of the program. This is an important finding for institutions to consider when educating their students regarding the meaning of accreditation. Additionally, students attributed heavy workloads in courses to accreditation requirements. While there is some truth to this perception, accreditation standards do not mandate a certain number of courses or contact hours. Thus, heavy course loads are more likely related to requirements established by the program itself.

This study has implications for programs that seek international accreditation for their pharmacy programs. First, students seem to largely understand the role of accreditation for institutions, but have misconceptions regarding how accreditation affects them as individuals. As students are arguably the greatest stakeholders in any academic program, these discrepancies should be addressed to ensure students have clear expectations for what accreditation means for them postgraduation. The second implication of this study is that students equate international accreditation with enhanced patient care practice and outcomes. Future studies should explore this finding with respect to the association between achieved learning outcomes and patient care abilities and how these uniquely relate to international settings. This will help international programs work with accreditation bodies to refine frameworks and standards to better support the needs of local practice settings.

This study has limitations that should be noted. The greatest limitations of the study were that it was conducted at one university and only a small sample size was recruited. However, this was meant to be an exploratory study, and we found similar ideas being presented across all focus groups. By limiting participants to graduates who were currently practicing, we may have missed gathering different perceptions from those not practicing. However, only six graduates from the program since its inception in 2011 were excluded based on this criterion. Second, we did not include a control group of participants from non-accredited institutions as we needed the findings from this initial study to define a topic guide and/or framework that we could later apply to studies involving these other participants. Finally, the study is based solely on student and alumni perspectives, and recruitment of other stakeholders for future studies will allow better conceptualization of international accreditation perspectives as a whole.

\section{CONCLUSION}

We have examined student perceptions about international accreditation for pharmacy degree programs. We conclude that participants had positive perceptions of international accreditation, as they believed accreditation increases the reputability of the program, ensures quality 


\section{American Journal of Pharmaceutical Education 2019; 83 (6) Article 6805.}

standards are maintained, and provides opportunities related to careers and postgraduate studies. Participants perceived that accreditation improved patient outcomes, largely through bettering their skills as practitioners. Misconceptions of accreditation emerged throughout the analysis, relating directly to recognition of accreditation and the benefits specific to the individual graduate. Results can be used to aid other programs in ensuring students are well informed regarding the purpose of accreditation and expected impacts on their degree. Future studies should be designed to determine the impact of international accreditation on the key domains identified by this study.

\section{ACKNOWLEDGMENTS}

Funding was provided by a grant from Qatar University (QUST-2-CPH-2017-4).

\section{REFERENCES}

1. Accreditation 2013, European Consortium of Accreditation for Accreditation in Higher Education. http://ecahe.eu/w/index.php/ Accreditation. Accessed September 21, 2017.

2. Van Zanten M, Norcini JJ, Boulet JR, Simon F. Overview of accreditation of undergraduate medical education programmes worldwide. Med Educ. 2008;42(9):930-937.
3. GPC 2017, Education. General Pharmaceutical Council. https:// www.pharmacyregulation.org/education. Accessed Sep 21, 2017. 4. PharmD Program Accreditation, Accreditation Council for Pharmacy Education. https://www.acpe-accredit.org/pharmdprogram-accreditation/. Accessed September 21, 2017.

5. Obtaining Accreditation 2017, Canadian Council for Accreditation of Pharmacy Programs. http://ccapp-accredit.ca. Accessed September 21, 2017.

6. Kheir N, Zaidan M, Younes H, El Hajj M, Wilbur K, Jewesson P. Pharmacy education and practice in 13 Middle Eastern countries. Am J Pharm Educ. 2008;72(6):Article 133.

7. Braithwaite J, Westbrook J, Pawsey M, Greenfield D, Naylor J, Iedema $\mathrm{R}$, et al. A prospective, multi-method, multi-disciplinary, multi-level, collaborative social-organisational design for researching health sector accreditation. BMC Health Serv Res. 2006;6:113.

8. Nasca TJ, Philibert I, Brigham T, Flynn TC. The next GME accreditation system - rationale and benefits. $N$ Engl $J$ Med. 2012;366:1051-1056.

9. Van Zanten M, McKinley D, Durante Montiel I, Pijano CV. Medical education accreditation in Mexico and the Philippines: impact on student outcomes. Med Educ. 2012;46(6):586-592.

10. Ibrahim H, Abdel-Razig S. Nair Medical students' perceptions of international accreditation. Int J Med Educ. 2015;6:121.

11. Yüksel İ. Graduate students' perception of standards and accreditation in higher education in Turkey: a qualitative analysis. Qualitative Rep. 2013;18(38):1-14.

Appendix 1. Representative Quotes Provided by Participants During Focus Group Discussions

\section{Theme 1: Influence on Education}

“... even the quality of the curriculum itself it should meet higher standards or even international standards so that helped us to be updated to be, to make sure that we are within like even reaching somehow the level of the most advanced countries in that specialties."

"Sometimes in terms of cultural thing, I feel more comfortable when I see patient from a western country, like this is what we used to practiced in [OSCE], most of them even are western and like the level of how much they interacting with us is similar to the Western patient idea."

"It was difficult in the beginning when I graduated I went to the field. I feel that I didn't know many things, I lacked many things in terms of knowledge yes but, later on when I built my knowledge and myself I felt that with time its easier for me to acquire and build up myself and increase my awareness and increase my knowledge. That's what made me a better clinical pharmacist and I think this what the college mainly aimed at you have the skills to be a very good pharmacist."

\section{Theme 2: Influence on Patient Care}

"Our curriculum was mainly based and more focusing on patient care, patient centered evidence based and it was mainly patients, I think our curriculum was good enough to prepare us take care of patients."

"When we were in PharmD program still not working, I felt that I had different approach than my preceptor, we talk to patients about allergies actually and we go more in depth so it leads to better patient outcomes at the end."

\section{Theme 3: Influence on the Individual}

"Because you look more stronger when you graduate from an accredited program rather than graduating from non-accredited program. So you know that the curriculum meets certain criteria for accreditation and when you have accreditation it means that the program that you have gone through is strong and your degree is more pronounced to people and more acceptable when you apply for a job or pursue other studies."

"I think some people still don't know when we do our clinical pharmacist job, some people they think its extra work and we are not doing the things that we should do."

"Yeah I would agree with [Name] because we really had an overload. Although we benefited, it was like really over load for students from our side, many subjects per semester, we have to focus on many different things." 